\title{
Identifying and analyzing motor skill responses in body movement and dance
}

\author{
Marta Castañer and Carlota Torrents \\ University of Lleida, Lleida, Spain \\ M. T. ANGUERA \\ University of Barcelona, Barcelona, Spain \\ MÁRIA DinuŠová \\ University of Lleida, Lleida, Spain \\ AND \\ GUDBERG K. JONSSON \\ University of Iceland, Reykjavik, Iceland \\ and University of Aberdeen, Aberdeen, Scotland
}

\begin{abstract}
The present article analyzes the diversity of motor skills related to three different kinds of instructions: descriptive, metaphoric, and kinesic, with a special emphasis on the detection of temporal patterns (T-patterns). Twelve undergraduates studying sport and physical education, but without experience in dance, were observed during 24 lessons of Body Movement, a discipline based on creative dance, mime dance, and motor skill improvisation. Using observational methodology and technology applied to movement, the aim of this article was to adapt the Observational instrument of Motor Skills (OSMOS) (Castañer, Torrents, Anguera, \& Dinušová, 2008) so as to create an instrument capable of analyzing the motor skill responses generated in lessons of Body Movement and Dance. The results, as reflected by the T-patterns detected, show that (1) participants try to generate their own motor skills but copy some fundamental components of the instructions, and (2) the criterion of stability in two configurations (support and axial) is the predominant category. Sequential and coordinated locomotion also appears to be very relevant.
\end{abstract}

\section{The Diversity of Motor Skills Related to Instructions}

Motor skills arise out of the combination of movement patterns that introduce the work of the body, both as a whole and in its various segments. Each sport contains motor skills with a specific configuration that give it its identity and singularity with respect to other sports and body movement activities (Jonsson et al., 2006). Indeed, motor skills can be observed as behavioral structures in all kinds of body movements and sport activities, but "although various disciplines have recognized the need to determine the possibilities of human movement, very few studies have considered the most effective way of observing, evaluating and analyzing the complexity of motor skills" (Castañer et al., 2009). The present study includes a criterion related to instructions in the OSMOS instrument (Castañer, Torrents, Anguera, \& Dinušová, 2008). The focus is on the form taken by motor skills, and thus we distinguish between those concerned with manipulation, those concerning stability, and those concerning skills of locomotion (Gallahue \& Cleland-Donnelly, 2003), all of which can be observed in any motor or sporting activity (Castañer et al., 2009).

The most common instructions used to develop motor skills in a dance context are those related to the problemsolving approach. Here we focused on three types of instructions - descriptive, kinesic, and metaphoric - which seek to foster individual diversity of body movement by enhancing the motor creativity of participants through problem solving (Lobo \& Winsler, 2006). Motor creativity is defined as the combination of perceptions into new motor patterns (Wyrick, 1968). We classified the instructions given by the instructor into the following three categories.

Kinesic. The instructor supports learning through specifically chosen motor examples or visual demonstrations, but does not propose that these be followed. This differs from modeling (a process whereby observers attempt to replicate a demonstrated behavior or action; McCullagh, Weiss, \& Ross, 1989), since the aim of the instruction is simply to serve as an example.

Descriptive. The instructor supports and guides the participants' independent process of problem-solving by 
posing questions using specific terminology of physical education or dance.

Metaphoric. The instructor supports and guides the participants' independent process of problem-solving by posing questions using metaphorical images or guided visioning.

In order to enhance motor creativity in dance classes, it is common for instructions to be based on open-ended questions that have to be responded to with improvised movement, so that participants experience the range of motor skills and choose the best one in each situation. These open-ended questions can be presented according to different instructional methods, but all of them can be considered problem-solving approaches (Beckmann \& Wichmann, 2005).

A dilemma in creative or improvisation dance classes is whether the creative process is best supported through instructional freedom, allowing participants to be flexible in their responses, or by imposing constraint through a rigid structure (Craft, 2005). This can be considered in terms of whether the creative source is prioritized as being within the participants (the outside in approach) or within dance knowledge or the instructor (working inside out) (Chappell, 2007). In creative and expressive movement, the instructor does not usually instruct participants to copy and does not give any motor examples, because it is expected that each participant will look for his or her own style, an individual development of the response. Nevertheless, participants do interact with one another in order to make their own motor-skill proposals that can then be examples to the rest. Moreover, the questions that serve as a stimulus may be of a different nature, since the instructor can describe the question or use other motivational factors, such as guided visioning or metaphors (for example, "move like an astronaut in space"), that can enhance motor creativity. Metaphorical images are widely used in dance as a resource with different purposes, such as creating, or even communicating with the audience (Nordin \& Cumming, 2007).

The purpose of this study is, through the detection of time patterns (T-patterns; Jonsson et al., 2006; Magnusson, 1996), to analyze (1) the influence of the three varieties of instruction identified above and described in the motor skill responses of the participants, and (2) the influence of these three varieties of instruction on the criteria of body, space, time, and interaction among participants during motor performance.

\section{METHOD}

\section{Design}

The design for this study is N/P/M (nomothetic/point/multidimensional; Anguera, Blanco-Villaseñor, \& Losada, 2001). It is nomothetic (several participants with a high level of motor interaction) since, as a whole, the participants can be considered at a nomothetic level due to the high level of motor interaction. It is point because we consider a single session with all the participants, and multidimensional because it combines a category system with a field format that enables us to manage six criteria that include 18 exhaustive and mutually exclusive categories. The data are Type IV (Bakeman, 1978).

\section{Participants}

The 12 participants (age range, 19-21) were recruited from among the total of 120 first-year sport and physical activity sciences undergraduates from Lleida University (INEFC-UdL). Although they had considerable experience in physical activities, they had no prior experience with dance classes. All participants attended the course called Body Movement, which was based on creative dance, mimedance, and improvisation; none of them had any experience in this kind of dance.

\section{The Instrument}

The observation of a natural context requires the use of the previously mentioned observation instrument, as well as the detection of T-patterns in the transcribed actions. Here, in an ad hoc version designed for this study, we used all aspects of the OSMOS instrument (Castañer et al., 2008), which includes instructions to enhance motor skills. A new criterion was thus included: instruction, which refers to the quantity and quality of the motor responses of the same category as those offered by the participant. This new criterion included the following categories: exact as the instruction (Mo), when the response is the same as the instruction proposed by the instructor; tendency of the instruction $(\mathrm{Mt})$, when the response is similar to the instruction proposed by the instructor; different motor response $(\mathrm{m})$, when the response is not similar to the instruction proposed by the instructor, or when there is no instruction; and other (A), when the responses do not agree with the instruction. This criterion enables us to observe the type of variations in the motor skills performed by participants, compared with the kinesic instruction of the instructor, or with their own responses after receiving instructions. For instance, if the participant exactly copies the instruction, the observer should mark the category exact as the instruction. If the response is similar but differs in the position of the body, the speed of movement, or the direction through space, the observer should mark the category tendency of the instruction. If the response differs in more than one category (body, space, or time), the observer should mark different from the instruction. Finally, if the observed participant performs an action that has nothing to do with the instruction, the observer should mark other. When there is no instruction, the observers can mark different from the instruction or other. The other criteria are those of the OSMOS instrument, referring to the motor skills of locomotion, stability, and manipulation (Castañer \& Camerino, 2006; Gallahue \& Cleland-Donnelly, 2003 ), along with the criteria of body, space, time, and interaction. Indeed, the instrument is based on changing criteria (stability, locomotion, manipulation, body-space, temporal, and interaction). The exception here is the temporal criterion, which has only one code (Time). ${ }^{1}$ It should be noted that all the categories within a criterion are mutually exclusive and may occur no more than once in each observation frame. The observers have to mark the skill category (stability, locomotion, or manipulation) which corresponds to each motor action, and indicate what kind of variation is produced, compared with the kinesic instruction or with the previous response of the participant after receiving the instruction. Table 1 describes all the criteria and categories of the OSMOS instrument.

This observation instrument helps us to analyze the following.

1. The total number of different responses, depending on the type of instruction or interaction or on the quantity of motor responses.

2. The influence of kinesic instructions in terms of generating responses that are the same as, or similar to, the instruction.

3. The type of responses generated by each type of instruction or interaction, the quality of motor skill responses, and the production of relevant T-patterns.

\section{Procedure}

Participants were videorecorded during 24 lessons of Body Movement, each lasting $50 \mathrm{~min}$ and taking place over a period of 2 months. The main activities were based on motor improvisations, mime dance, and contact improvisation. The instructor randomly used the three 
Table 1

Adaptation of OSMOS Criteria for This Research

\begin{tabular}{|c|c|}
\hline Criteria & Categories \\
\hline \multirow[t]{4}{*}{ Instruction } & Exact instruction (Mo): Response that is the same as the instruction proposed by the instructor. \\
\hline & Tendency instruction $(\mathrm{Mt})$ : Response that is similar to the instruction proposed by the instructor. \\
\hline & Different instruction $(\mathrm{m})$ : Response that is not similar to the instruction proposed by the instructor or when there is no instruction. \\
\hline & Other (a): Motor responses that do not agree with the instruction. \\
\hline \multirow[t]{3}{*}{ Stability } & $\begin{array}{l}\text { Support stability (Es): Motor skills that enable body equilibrium to be maintained over one or several body support points, } \\
\text { without producing locomotion (e.g., balancing actions). }\end{array}$ \\
\hline & $\begin{array}{l}\text { Elevation stability (Ed): Motor skills that enable the body to be projected by elevating it in space, without producing locomotion } \\
\text { (e.g., jumps). }\end{array}$ \\
\hline & $\begin{array}{l}\text { Axial stability (Ea): Motor skills that enable body axes and planes to be varied from a fixed point, without producing locomotion } \\
\text { (e.g., turns). }\end{array}$ \\
\hline \multirow[t]{3}{*}{ Locomotion } & Propulsion-stop locomotion (Lp): Motor skills that occur at the start and finish of a body movement through space. \\
\hline & $\begin{array}{l}\text { Sequential rebalance locomotion (Ls): Motor skills that enable a space to be moved through via the priority sequence of actions } \\
\text { of the segments of the lower limbs (bipedestrian locomotion) or upper limbs (in inversion). }\end{array}$ \\
\hline & $\begin{array}{l}\text { Simultaneous coordinated locomotion (Lc): Motor skills that enable a space to be moved through via the combined action of all } \\
\text { body segments (e.g., quadrupedian locomotion). }\end{array}$ \\
\hline \multirow[t]{2}{*}{ Manipulation } & Impact manipulation (Mi): Motor skills in which certain body zones briefly come into contact with objects or other people. \\
\hline & $\begin{array}{l}\text { Conduction manipulation (Mc): Motor skills in which certain segments handle (for a given period of time) objects or other } \\
\text { people. }\end{array}$ \\
\hline \multirow[t]{7}{*}{ Body-space } & Body changes (c): Evident variations in body posture and gestures. \\
\hline & Change in spatial direction $(\mathrm{d})$ : Variations in the spatial direction of the movement. \\
\hline & $\begin{array}{l}\text { Change of spatial level (n): Change between the different spatial levels (low or floor work, middle or bipedestrian work, upper or } \\
\text { aerial work). }\end{array}$ \\
\hline & Combination of variations in body posture/gestures and spatial direction (CD). \\
\hline & Combination of variations in body posture/gestures and spatial level (CN). \\
\hline & Combination of variations in spatial level and direction (ND). \\
\hline & Combination of variations in body posture/gestures, level, and spatial direction (CND). \\
\hline Temporal & Time $(\mathrm{t})$ : When there is a clearly observable change in the tempo of a motor action with respect to the previous one. \\
\hline \multirow[t]{2}{*}{ Interaction } & Dyadic interaction (Id): Interaction with a partner. \\
\hline & Group interaction (Ig): Interaction with more than one other group member. \\
\hline
\end{tabular}

varieties of instructions (descriptive, metaphoric, and kinesics) to explain the different tasks. In each task, participants had $5 \mathrm{~min}$ to explore, according to their own motor ideas, the instructions given. All sessions were videorecorded after an adaptation phase to the camera, the aim being to avoid any reactive effect prior to the study period.

The recording instrument used to codify OSMOS was the ThemeCoder software, an interactive video-coding program which allows effective recording of the time of occurrence of behavioral events - that is, their beginnings and endings (PatternVision, 2001; see Figure 1). This enables observers to indicate the motor skill category corresponding to the type of variations in the motor skills performed by the participants, as well as the kind of variation produced in each situation.

Three different observers used the ThemeCoder software to transcribe all the recordings of observation sessions and obtain the corresponding event frequencies; this involved calculating the number of each kind of registered event, as well as the number of occurrences of each category independently of the other categories. In order to control the quality of data (Blanco-Villaseñor, 1993; Blanco-Villaseñor \& Anguera, 2000; Jansen, Wiertz, Meyer, \& Noldus, 2003) the Kappa coefficient was obtained (.97 for all criteria and all sessions). This coefficient provides a satisfactory guarantee of data quality.

In order to fulfill the study objectives, we searched for T-patterns regarding the three varieties of instructions, a T-pattern being a structure detected in some sequential data that must be fitted and consolidated on the basis of the time patterns obtained. For the detection of T-patterns, we used the THEME software (Magnusson, 1996, 2000, 2005), which allows the analyst to detect complex and repeated temporal patterns even when a multitude of unrelated events occur in between components of the patterns. This typically makes them invisible to both the naked eye and (to our knowledge) to currently available statistical methods and software (for the theoretical basis and an explanation of the model and method, see Magnusson, 1996, 2000, 2005).

The basic assumption of this methodological approach is that the temporal structure of a complex behavioral system is largely unknown but may involve a set of a particular type of repeated T-patterns composed of simpler, directly distinguishable event types, which are coded in terms of their beginning and end points (such as
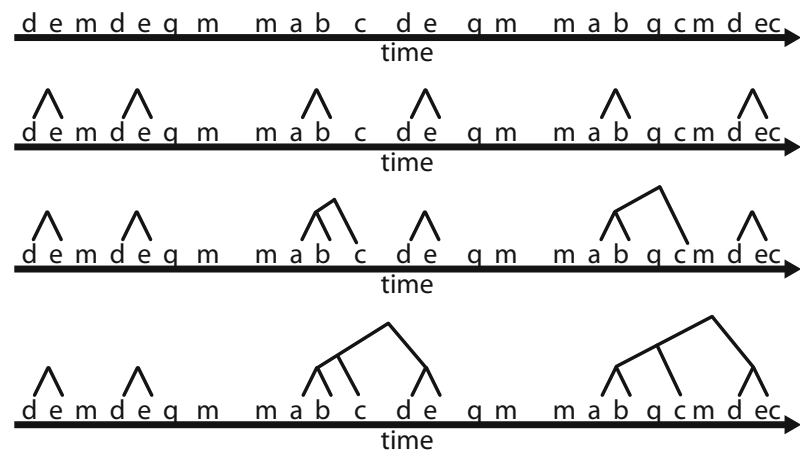

Figure 1. Formation of a T-pattern from a simple T-pattern of (ab) pairs to more complex T-patterns. From the behavior sequence depicted at the top, Theme detects T-patterns from simple ones, such as T-patterns of (ab) in the second row, to more complex ones, such as the T-pattern at the bottom. 


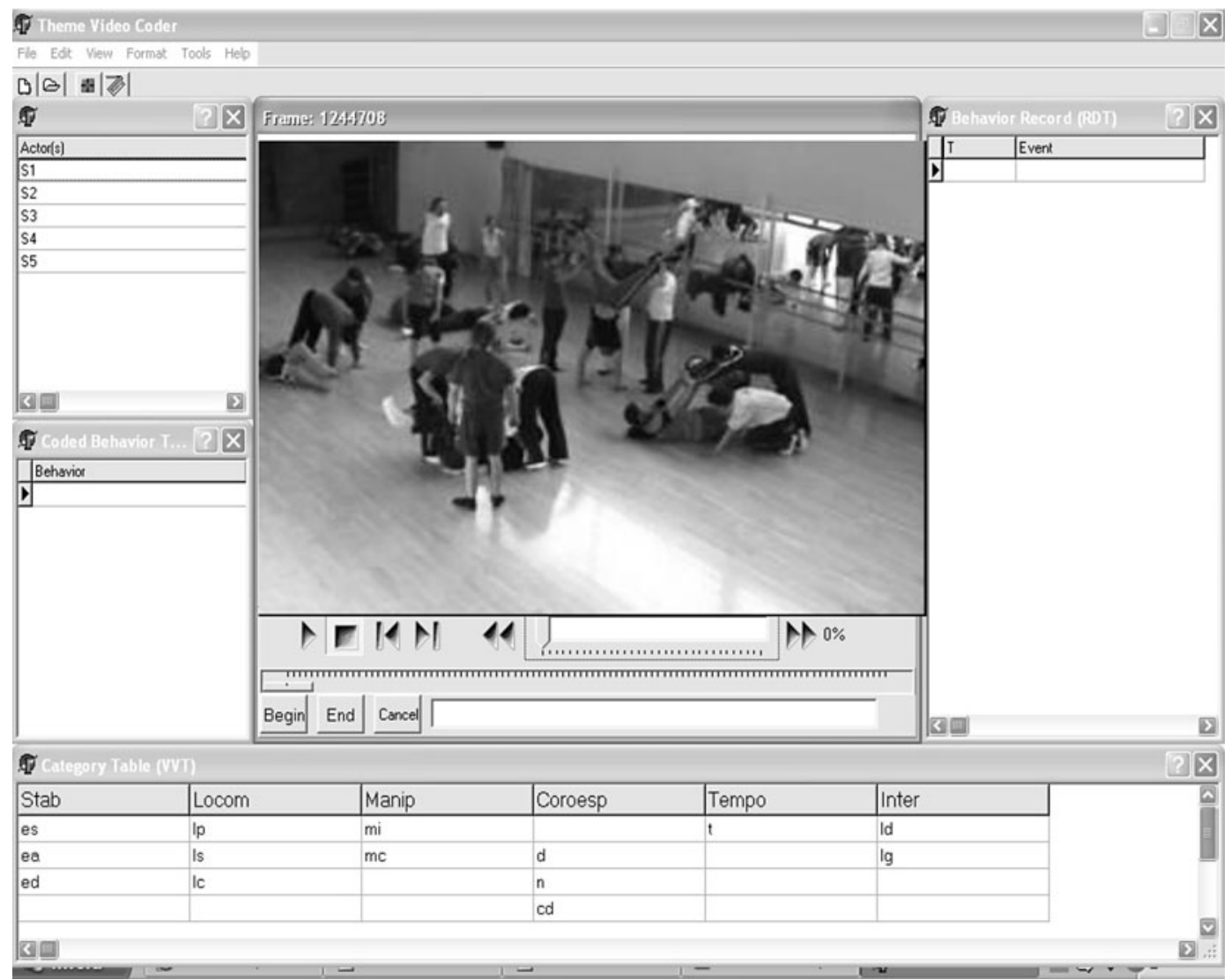

Figure 2. Screen capture of ThemeCoder with OSMOS codes.

"dog begins walking" or "dog stops running"). The kind of behavior record (as a set of time point series or occurrence time series) that results from coding of behavior within a particular observation period (here called T-data) constitutes the input to the T-pattern definition and detection algorithms.

Essentially, within a given observation period, two actions, $a$ and $b$, occurring repeatedly in that order or concurrently, are said to form a minimal T-pattern $(a b)$ if more often than expected by chance and assuming as h0 independent distributions for $a$ and $b$, there is, approximately, the same time distance between them. Instances of $a$ and $b$ related by that approximate distance then constitute the occurrence of the $(a b)$ T-pattern and its occurrence times are added to the original data. More complex T-patterns are consequently and gradually detected as patterns of simpler already-detected patterns through a hierarchical bottom-up detection procedure. Pairs (patterns) of pairs may, therefore, be detected; for example $\{[(a b) c](d e)\}$, and so on (see Figure 2). Special algorithms deal with potential combinatorial explosions due to redundant and partial detection of the same patterns using an evolution algorithm (completeness competition), which compares all detected patterns and lets only the most complete patterns survive. Since any basic time unit may be used, T-patterns are, in principle, scale-independent, although only a limited range of basic unit sizes is relevant in any given study (Jonsson et al., 2006).

Table 2

Description of Number of Tasks Proposed Following Each Variety of Instruction, Number of Motor Responses Performed by Participants After Instructions During Observation Sessions, and Number of Relevant T-Patterns Obtained From All Motor Response Recordings in Each Lesson of Body Movement

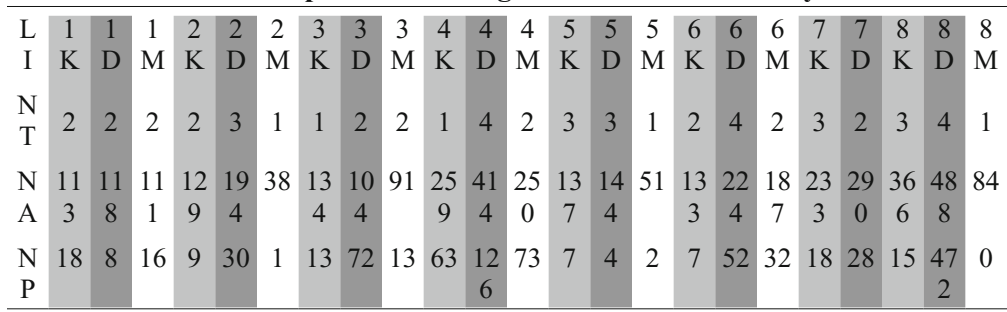

Note- L, lesson; I, instruction; NT, number of tasks; NA, number of motor responses; NP, motor response recordings; K, kinesic instruction; D, descriptive Instruction; M, metaphoric instruction. 


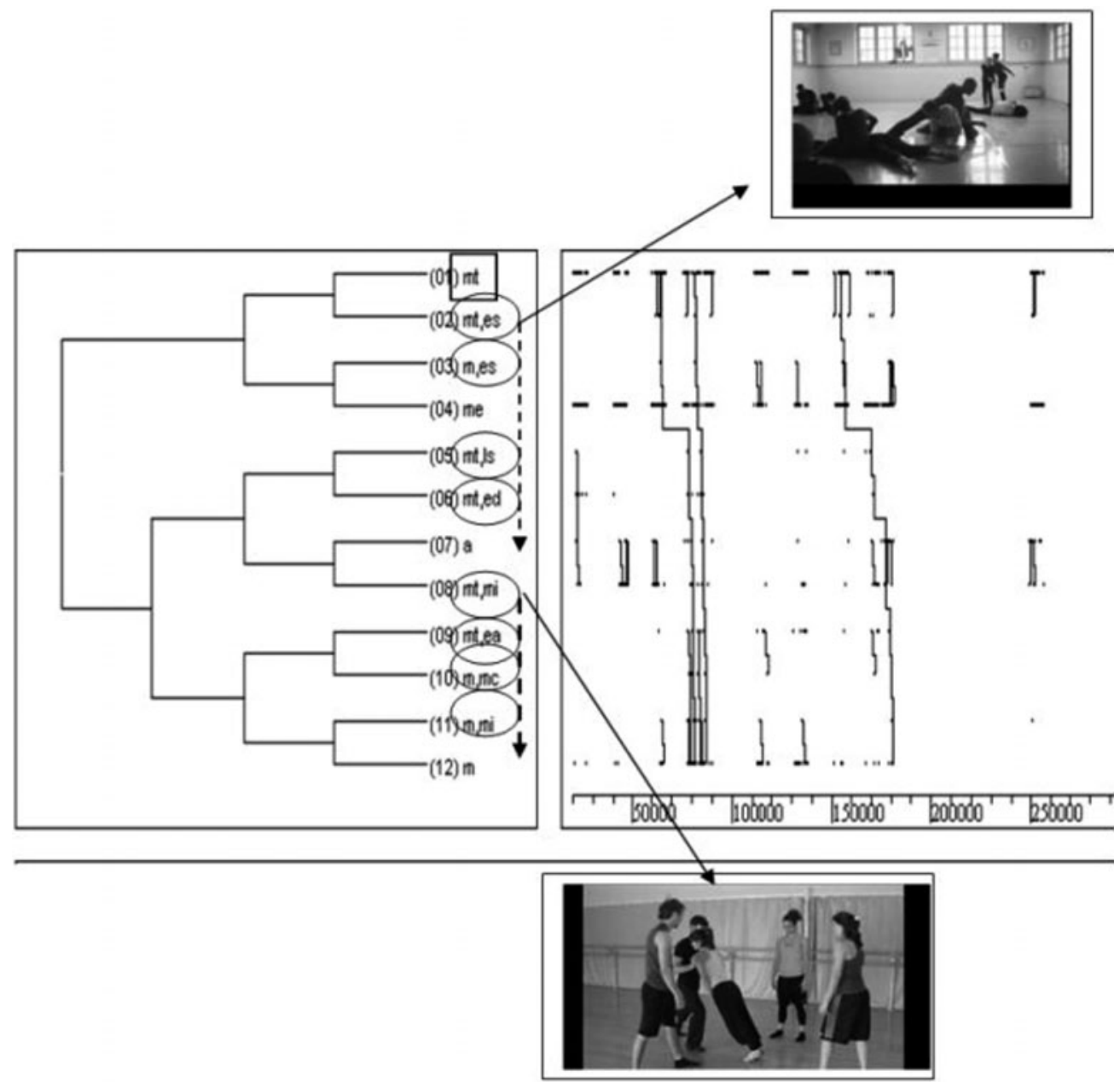

Figure 3. T-pattern related to kinesics instruction. This relevant T-pattern $(p<.005)^{2}$ shows for the first criteria of instruction (marked by a square) that the participants vary some characteristics of the initial instruction (Mt). They also try to explore other motor skill combinations related to the instruction (m); the exact instruction (Me) also appears frequently. An example of motor skills criteria we can observe (marked by a circle) in this T-pattern can be when a participant makes a static rebalance (Es), runs (Ls) and jumps (Ed), then stops (a). It continues in contact with another partner (Mi) to do turns (Ea) and also combining impact manipulation (Mi) and conduction manipulation (Mc) skills with the partner.

\section{RESULTS}

The number of T-patterns detected should be influenced by the number of tasks proposed in each session, the topic of that session, and the number of motor responses (see Table 2). In order to analyze the most frequent variations of the observed motor skills we took into account the first six frequencies and the relevant T-patterns obtained by analyzing all the motor skills performed by participants, depending on the variety of instruction and the session.

The frequencies show that when the task is introduced using a kinesic instruction, participants usually copy some important characteristics of this instruction, in line with what we have described above for the tendency instruction (Mt); however, they try to vary other aspects, especially those related to time ( $\mathrm{t}$ ) and body posture or gestures (c). In other words, the most common response is the tendency instruction (Mt). The exact copy of the example (Me) also appears frequently, more often than do responses completely different from the kinesic instruction (m). In the last two sessions, where contact improvisation was introduced, responses completely different from the kinesic instruction (m) were almost nonexistent, and the last session is the only one where the exact copy (Me) was predominant. This less frequent use of motor creativity may be due to the fact that the tasks were quite different to those used in the previous sessions and participants needed to rely more on the copy. The fourth session, which focused on the exploration of external time (the instructor asked the participants to follow different rhythms with free motor skills), is the only one where participants generated a greater number of different motor responses (m) than copies of the kinesic instruction (Me). This is probably because participants had to react spontaneously to the rhythm without having time to prepare or think about their movement. Nevertheless, the tendency instruction (Mt) 


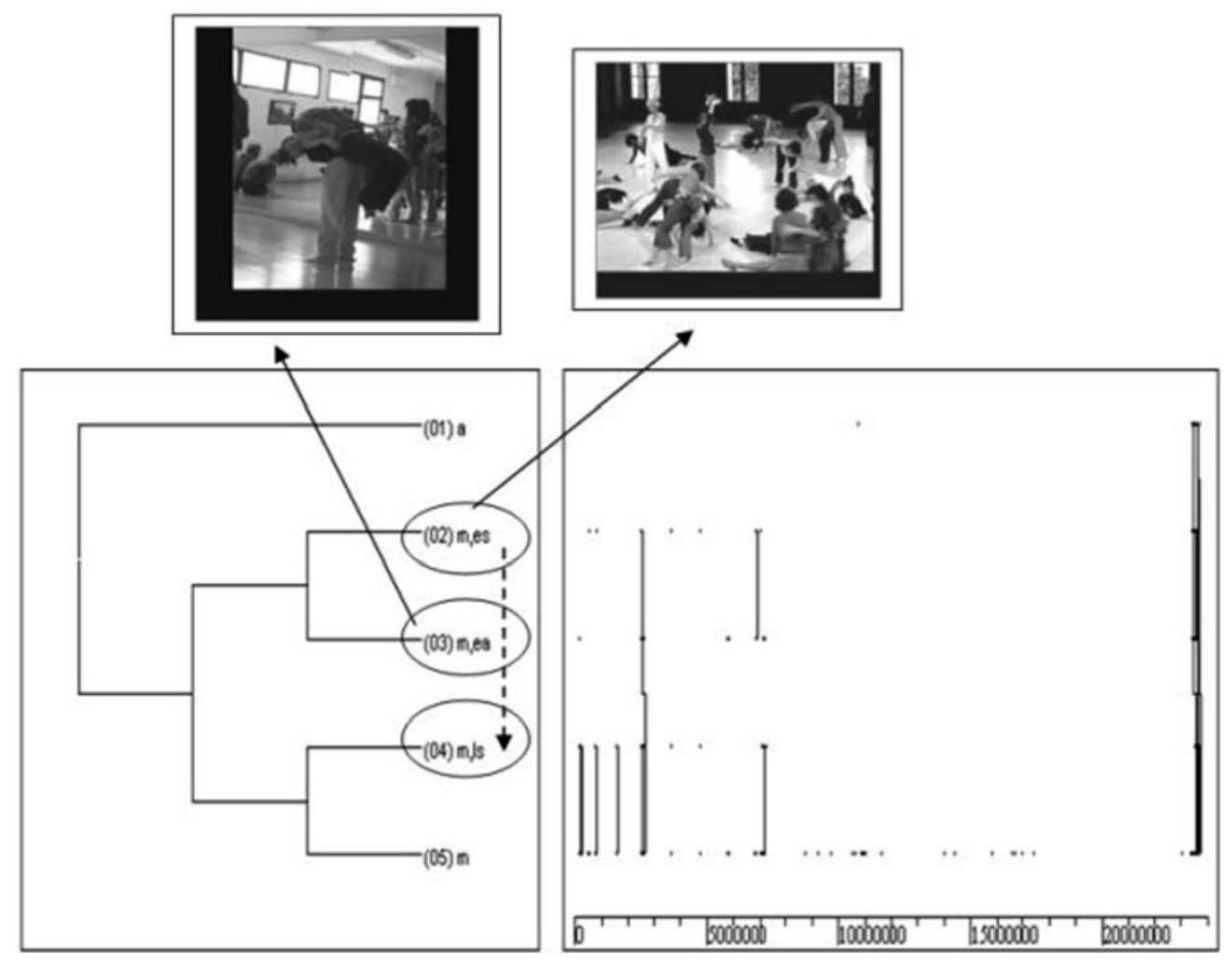

Figure 4. T-pattern related to descriptive instruction. This relevant T-pattern $(p<.005)$ shows that some participants do not understand the instruction very well, since they respond with motor actions that do not agree with the proposal (a). They then use stability and locomotion skills, and repeat some of the responses used previously (m). Responses related to the first criterion are marked by a square. An example focused only on motor skills criteria that we have marked by a circle could be: The participant stands up (Es), he turns on his vertical axis (Ea), then he runs away (Ls).

was still the most frequent. Completely different motor responses $(\mathrm{m})$ only appear among the six most common responses in this fourth session and also in the fifth (focused on the exploration of effort).

Participants tend to repeat the type of motor skill proposed by the instructor. Moreover, the use of a specific motor skill category depends on the type of task; for instance, manipulation skills require interaction with a partner, whereas for locomotion skills the participant must be able to move through space. With regard to interaction, when the instruction contained an example of kinesics performed by a couple, participants mainly interacted in pairs, as they have inferred to do from the instruction.

Event frequency charts (see Appendix A) show that when instructions for the task are given using a kinesic instruction, participants usually copy some important characteristics of the instruction; in other words, the most common response is the tendency instruction (Mt). Although the exact copy of the example (Me) is ranked first, the sum of all the responses corresponding to the tendency instruction reveals that they are the most widely used form. The most common variation of the instruction proposed is the use of manipulative skills, of impact (Mi), and of conduction $(\mathrm{Mc})$, followed by different types of stability skills: support, elevation, and axial stability.
Analysis of the T-patterns obtained from tasks introduced using a kinesic instruction shows that the most frequent pattern detected is the relationship between responses that reproduce the instruction (Me), followed by motor responses that change one of the characteristics (Mt), usually time $(\mathrm{t})$ or body posture or gestures $(\mathrm{c})$, where these are the most susceptible to change. However, when we focus on the motor skills criteria related to the type of instructions, it can be seen that very rich T-patterns are detected when using a kinesic instruction. It seems that this type of instruction offers more ideas and possibilities to participants. One relevant T-pattern (see Figure 3) shows that although participants vary some characteristics of the tendency (Mt), they try different skills. They also seek to explore different motor skill combinations related to the instruction $(\mathrm{m})$ by using stability and manipulation skills ( $\mathrm{m}$, Es-m, Mi-m, Mc). Participants also produced responses that do not agree with the proposal (a). Generally, when a kinesic instruction is used, the participants' initial response corresponds to a tendency instruction or an exact instruction. They then try to vary the skills used (Mt) and also to vary completely the instruction (m). In this case, the most frequently used motor skills are those related to manipulation. An example of the motor sequence for this T-pattern is given in Figure 3. 


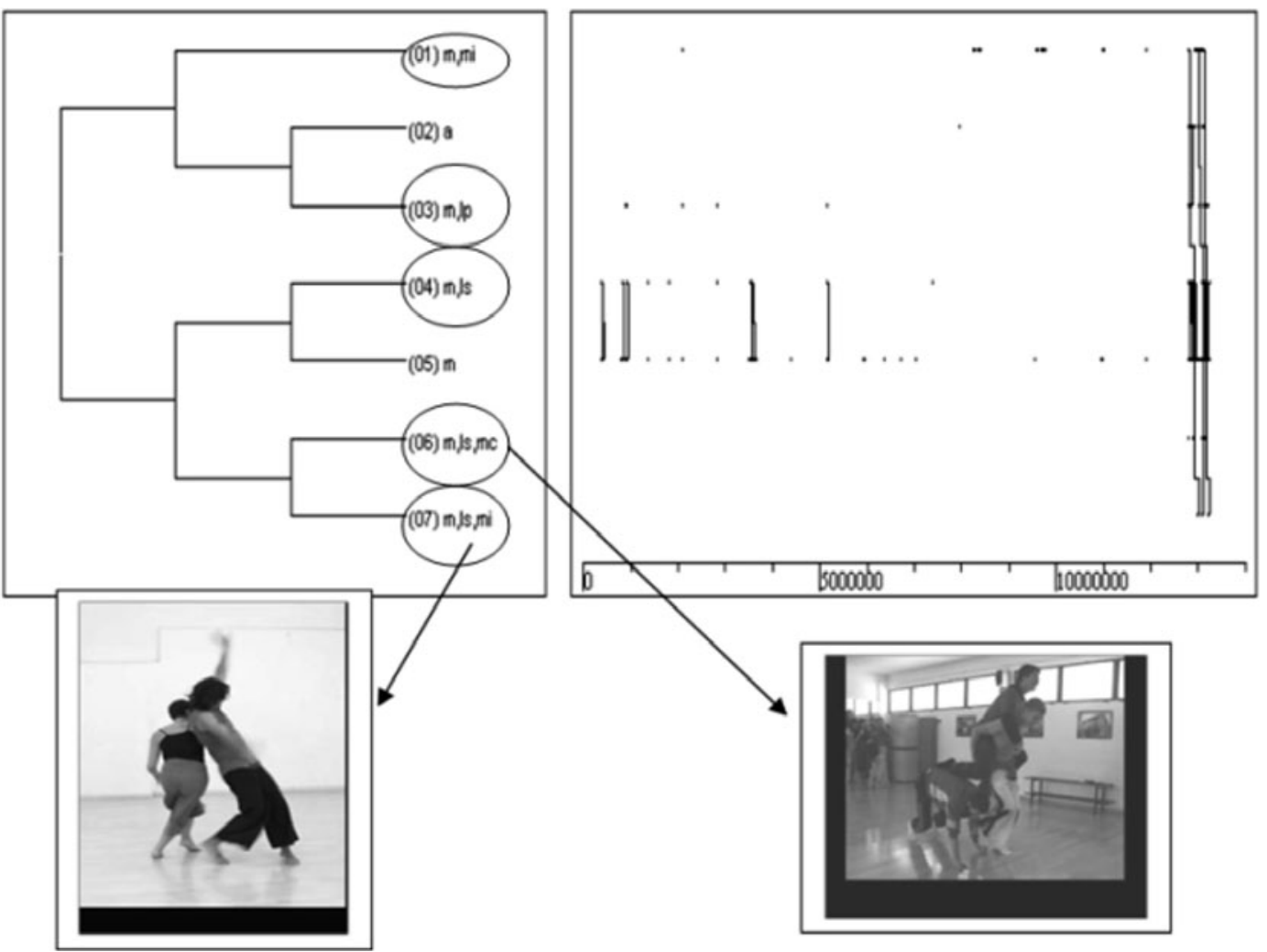

Figure 5. A relevant T-pattern related to metaphoric instruction $(p<.005)$. It can be seen that manipulative and locomotion skills are frequently used by participants, as is a combination of both $(\mathrm{m}, \mathrm{Ls}, \mathrm{Mc}-\mathrm{m}, \mathrm{Ls}$, Mi). Participants also repeat some of the responses they have generated previously. An example would be: The participant is in contact with a partner (Mi), speaks to agree with something without motor actions (a), then starts locomotion skill (Lp) and runs or walks (Ls), then suddenly combines this sequential locomotion skill with a conduction manipulation skill (Mc), finishing with an impact manipulation skill (Mi) in order to be alone.

With regard to descriptive instructions, the frequencies show that there are more variations here than in the tasks that use kinesic instructions. In all sessions, participants tend to vary the skill categories more and offer a wider range of motor responses. Once again, the changes with the highest frequency are related to body posture (c) and rhythm (t), although some sessions also include a number of space level changes. If we focus on motor skill frequencies when using a descriptive instruction, we can see that participants most frequently propose impact manipulation (Mi) and stability (Es, Ea, Ed) skills. Locomotion skills are also used, but less frequently (see Appendix B).

The corresponding T-patterns obtained show that when participants receive a descriptive instruction, they usually change or enrich their previous motor responses in the search for modifications, in contrast to what occurs with the kinesic instruction. In this case, they had to produce their own movements; generally, therefore, we observe different complete movements, because they are thinking about final motor responses, not only about a specific variety.

One relevant T-pattern (see Figure 4) shows that some participants seem not to understand the verbal instruction very well; this may be because they haven't received a kinesic reference from the instructor, so they respond with motor actions that do not agree with the proposal (a). They then use support and axial stability motor skills and sequential locomotion skills, and also repeat some of the responses used previously. An example of the motor sequence for this T-pattern is described in Figure 4.

When analyzing the motor skills generated by instructions given using a metaphorical image or guided vision, the frequencies show a very similar behavior to that observed in the tasks instructed using a description. The changes observed most frequently are related to body posture (c) and time (t). Space changes are infrequent but do appear in two lessons, whereas all lessons contain variations of the skill category.

Analysis of all the frequencies shows that interaction with partners produces motor responses that do not agree with the proposal (a). This type of response appears only when there is an interaction with partners, and never when they work alone. This is likely due to the search for a verbal agreement between participants prior to exploring the task, and probably wouldn't have happened if the participants had been contemporary dancers or expert improvisers. Nevertheless, after the agreement, participants responded in a more varied way than when performing without interaction. It can also be seen that at the beginning of the study period we recorded more of these types 
of motor response (a) than in the subsequent sessions of body movement. With regard to motor skills, the event frequency chart (see Appendix C) shows that when a metaphoric instruction is used, participants respond with all types of motor skills. Note that responses that do not agree with the instructor's proposals are less frequent here than in the case of the other instructions, probably because the metaphor helps students to understand the task. One relevant T-pattern (see Figure 5) related to metaphoric instruction shows that manipulative and locomotion skills are frequently used by participants, as is a combination of both (m, Ls, Mc-m, Ls, Mi). Participants also repeat some of the responses they have generated previously. An example of the motor sequence for this T-pattern is described in Figure 5.

\section{CONCLUSION}

It would seem that all three varieties of instruction can help participants enhance their motor creativity, although descriptive and metaphoric instructions are better at encouraging participants to search for self-expression and creativity. Descriptive instructions also seem to generate more varied motor responses, although sometimes they can be more confusing than kinesic or metaphoric instructions. Therefore, the use of one variety of instruction or another may depend on the aim of the task or the level of the dancers involved. Kinesic and metaphoric instruction might be useful for beginners, whereas expert dancers may respond more divergently, using descriptive instructions. In contrast, although the use of descriptive instruction with beginners could enhance the exploration of more varied motor responses, the metaphoric approach might be more motivating for both beginners and advanced participants. We therefore propose the responsive use of all three varieties of instructions, depending on the level of participants and the aims of the tasks.

To summarize, the results show the following.

1. When there was a kinesic instruction, participants generally produced a significantly greater number of different motor skills $(\mathrm{m})$ rather than exact reproductions $(\mathrm{Me})$ of the pattern proposed by the instructor, although they did copy certain characteristics (Mt). Descriptive and metaphoric instructions seem to generate more varied motor responses than does the kinesic approach. This is especially clear when using descriptive instructions, although it should be noted that metaphors help participants to understand the task and to be more motivated.

2. There were significant variations of motor responses in all kinds of tasks with regard to the category of time (t) and body posture and gestures (c). Space changes (n, d) or variation in the type of interaction (Id, Ig) were uncommon following an instruction, whereas changes in the skill categories were especially evident in the tasks without instruction. Comparing the three categories of instructions, it can be seen that the most frequent motor skills used by students are simultaneous coordination (Ls) and sequential rebalance (Lc) when responding to a metaphoric instruction. Stability skills usually appear in the three types of support, elevation, and axial when descrip- tive instructions are used, whereas impact and conduction manipulation skills can be observed when using kinesic instructions.

3. It was also evident that interaction with partners generates a different behavior than individual work does, because participants try to agree with their partners. Moreover, the interaction seems to inspire participants and helps them feel more creative. The present study raises a number of questions that could stimulate new research in what is a largely unexplored field. Indeed, there is no empirical evidence regarding the best way to enhance motor creativity in dance, and the following questions all require further consideration: Is the absence of any instruction as an example really a decisive factor? Can instructions foster the production of divergent motor skill responses among participants? Can the use of metaphorical images during instructions help to guide learners' own processes of problem-solving related to the diversity of motor skills?

\section{AUTHOR NOTE}

We gratefully acknowledge the support of the Catalan (Spain) government project Innovacions en l'avaluació de contextos naturals. Observació de les respostes motrius en l'expressió corporal i la dansa (AGAUR-PR-INEFC). We also gratefully acknowledge the support of the Spanish government project Avances tecnológicos y metodológicos en la automatización de estudios observacionales en deporte (Dirección General de Investigación, Ministerio de Ciencia e Innovación) [Grant PSI2008-01179]. Correspondence concerning this article should be addressed to M. Castañer, Laboratori d'Observació de la Motricitat, INEFC-Lleida, Pda. Caparrella S/N, Lleida 25192, Spain (e-mail: castaner@inefc.udl.cat).

\section{REFERENCES}

Anguera, M. T., Blanco-Villaseñor, A., \& Losada, J. L. (2001) Diseños observacionales, cuestíon clave en el proceso de la metodología observacional. Metodología de las Ciencias del Comportamiento, 3, 135-161.

BAKEMAN, R. (1978). Untangling streams of behavior: Sequential analysis of observation data. In G. P. Sackett (Ed.), Observing behavior: Data collection and analysis methods (Vol. 2, pp. 63-78). Baltimore: University Park Press.

Beckmann, H., \& Wichmann, K. (2005). The acquisition of motor skills-A problem solving approach. International Journal of Physical Education, 42, 120-127.

BlanCo-VILlaseñor, A. (1993). Fiabilidad, precisión, validez y generalización de los diseños observacionales. In M. T. Anguera (Ed.), Metodología observacional en la investigación psicológica (pp. 149261). Barcelona: P.P.U.

Blanco-Villaseñor, A., \& Anguera, M. T. (2000). Evaluación de la calidad en el registro del comportamiento: Aplicación a deportes de equipo. In E. Oñate, F. García-Sicilia, \& L. Ramallo (Eds.), Métodos numéricos en ciencias sociales (pp. 30-48). Barcelona: Centro Internacional de Métodos Numéricos en Ingeniería.

Castañer, M., \& CAmerino, O. (2006). Manifestaciones básicas de la motricidad. Lleida, Spain: Universitat de Lleida.

Castañer, M., Torrents, C., Anguera, M. T., \& Dinušová, M. (2008, August). Identifying and analysing motor skills answers in the corporal expression and dance through OSMOS. In A. J. Spink, M. R. Ballintijn, N. Bogers, F. Grieco, L. Loijens, L. Noldus, et al. (Eds.), Proceedings of the Sixth International Conference on Methods and Techniques in Behavioral Research (pp. 158-160). Maastricht, the Netherlands: Noldus Information Technology.

Castañer, M., Torrents, C., Dinušová, M., Camerino, O., Jonsson, G. K., \& Anguera, M. T. (2009). How to observe body movement: Hidden patterns of motor skills using OSMOS. Manuscript submitted for publication.

Chappell, K. (2007). The dilemmas of teaching for creativity: Insights 
from expert specialist dance teachers. Thinking Skills \& Creativity, 2, 39-56.

CRAFT, A. (2005). Creativity in schools: Tensions and dilemmas. London: Routledge.

Gallahue, D., \& Cleland-Donnelly, F. (2003). Development of physical education for all children. Champaign, IL: Human Kinetics.

Jansen, R. C., Wiertz, L. F., Meyer, E. S., \& Noldus, L. P. J. J. (2003). Reliability analysis of observational data: Problems, solutions, and software implementation. Behavior Research Methods, Instruments, \& Computers, 35, 391-399.

Jonsson, G. K., Anguera, M. T., Blanco-Villaseñor, A., Losada, J. L., Hernández-Mendo, A., Ardá, T., ET AL. (2006). Hidden patterns of play interaction in soccer using SOF-CODER. Behavior Research Methods, Instruments, \& Computers, 38, 372-381.

Lobo, Y. B., \& WinsLer, A. (2006). The effects of a creative dance and movement program on the social competence of head start preschoolers. Social Development, 15, 501-519.

MAGNusson, M. S. (1996). Hidden real-time patterns in intra- and interindividual behavior. European Journal of Psychological Assessment, 12, 112-123.

Magnusson, M. S. (2000). Discovering hidden time patterns in behavior: T-patterns and their detection. Behavior Research Methods, Instruments, \& Computers, 32, 93-110.

MaGNUSSON, M. S. (2005). Understanding social interaction: Discovering hidden structure with model and algorithms. In L. Anolli, S. Duncan, Jr.,
M. S. Magnusson, \& G. Riva (Eds.), The hidden structure of interaction: From neurons to culture patterns (pp. 3-22). Amsterdam: IOS Press.

McCullagh, P., Weiss, M. R., \& Ross, D. (1989). Modeling considerations in motor skill performance: An integrated approach. In K. B. Pandolf (Ed.), Exercise and sport science reviews (Vol. 17, pp. 475513). Baltimore: Williams \& Wilkin.

Nordin, S. M., \& Cumming, J. (2007). Where, when, and how: A quantitative account of dance imagery. Research Quarterly for Exercise \& Sport, 78, 390-395.

PatternVision, THEME Coder [software] (2001). Retrieved January 15,2002 , from www.patternvision.com.

WYRICK, W. (1968). The development of a test of motor creativity. Research Quarterly, 39, 756-765.

\section{NOTES}

1. The temporal criterion was considered to be univalent to record when there was a significant change in tempo with respect to each one of the motor responses being generated.

2 . The probability that the critical interval relationship occurred by chance is $p$. The value .005 is the significance value used by the critical interval test (Magnusson, 2000, p. 99). This critical interval test is based on the null hypothesis that A and B are independently and purely randomly (Poisson distribution) distributed over the observation period (Magnusson, 2000, p. 107).

\section{APPENDIXA}

\section{Event Frequency Chart}

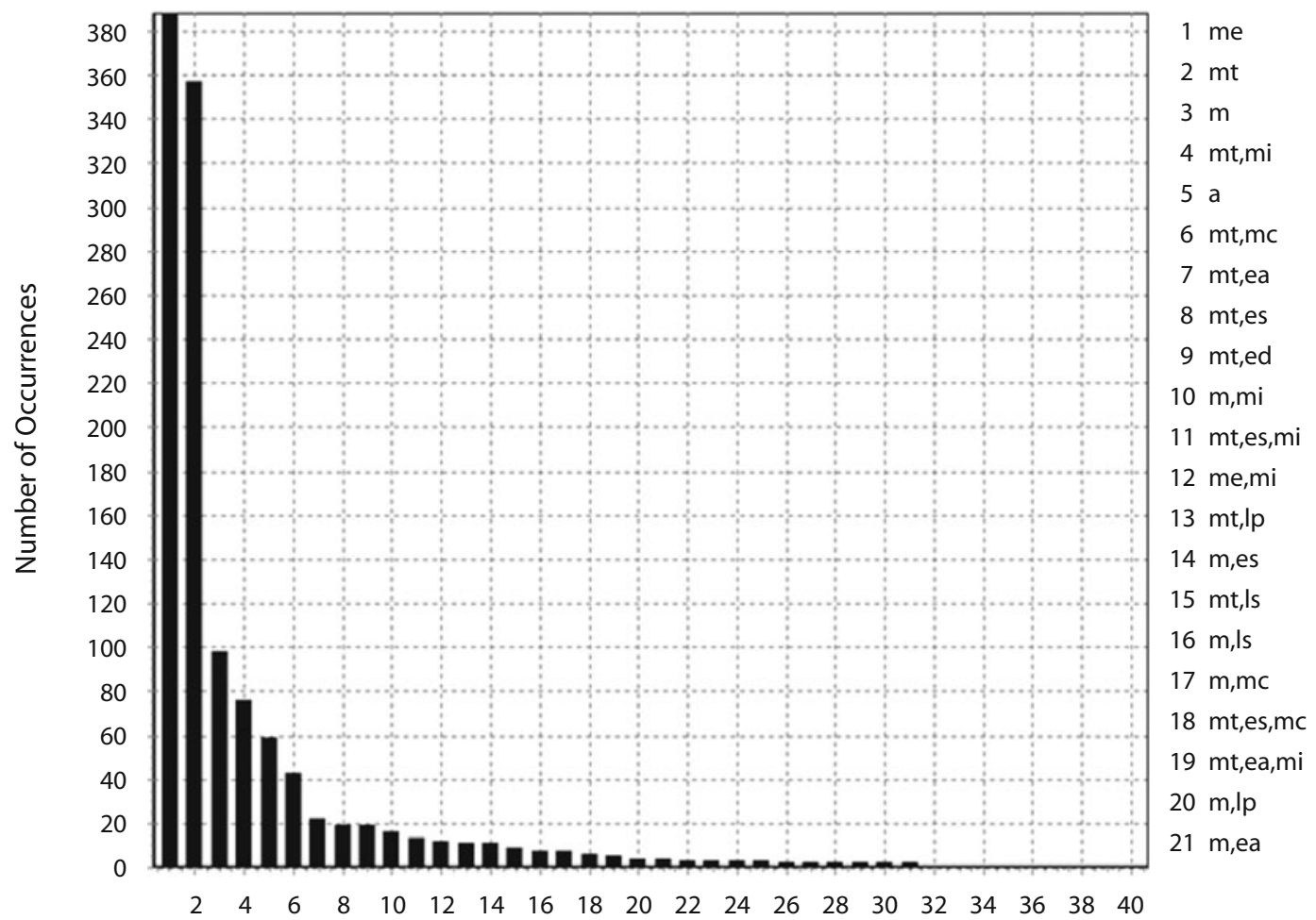

Event Types

Figure A1. Event frequency chart of kinesic instructions. The frequencies show that participants usually copy some important characteristics of the instruction; the most common response is the tendency model (Mt). Although the exact copy of the example (Me) is ranked first, the sum of all the responses corresponding to the tendency instruction shows that they are the most widely used forms. The most common variation of the model proposed is the use of manipulative skills, of impact (Mi), and of conduction (Mc). There then appear all types of stability skills: support stability, elevation, and axial stability. 


\section{APPENDIX B}

\section{Event Frequency Chart}

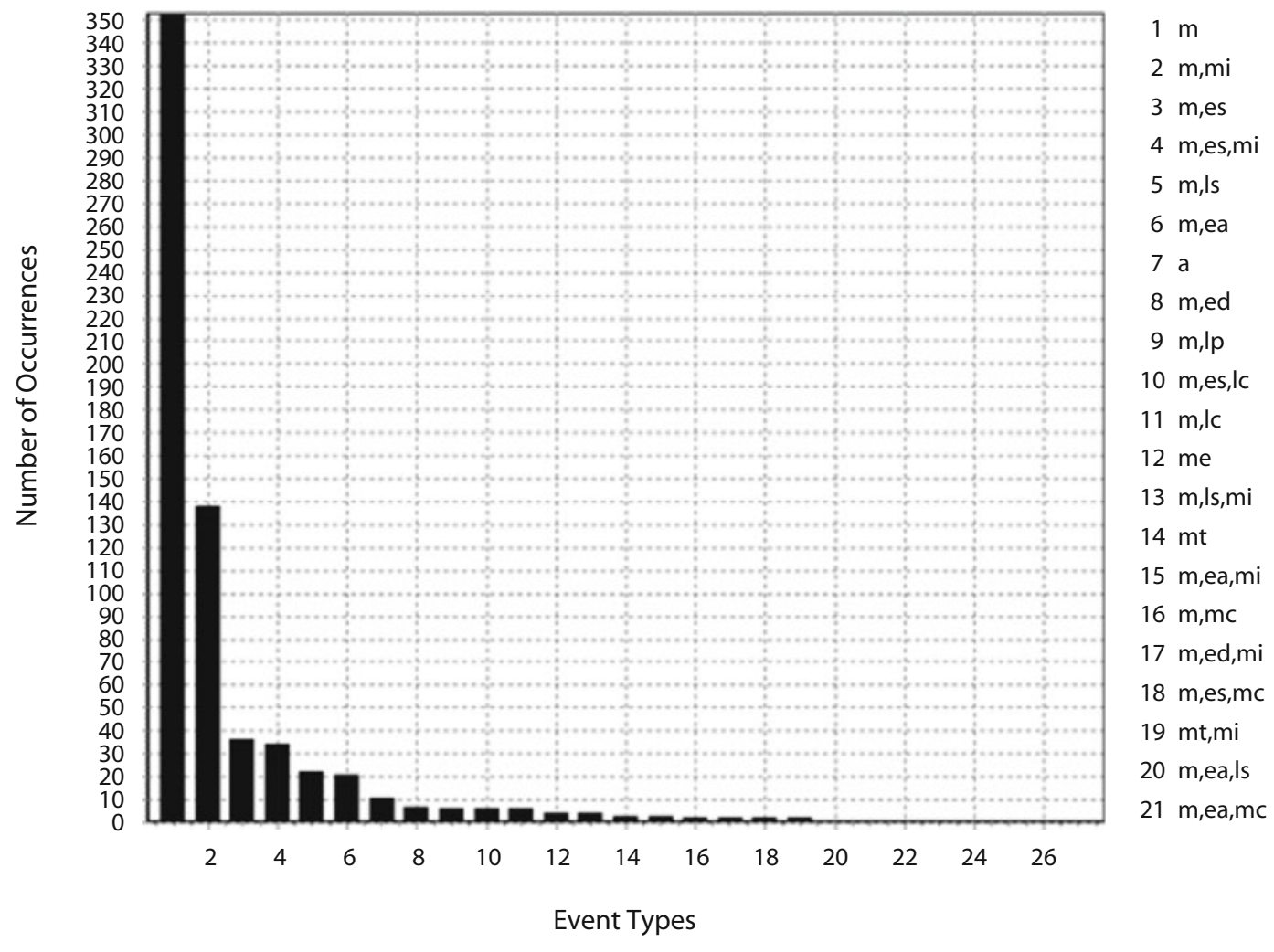

Figure B1. Event frequency chart of descriptive instructions. When a descriptive instruction is used, participants most often propose impact manipulation (Mi) and stability (Es, Ea, Ed) skills. Locomotion skills are also used, but not so frequently. An example of this T-pattern would be when a participant achieves a static equilibrium, then runs, jumps, then stops, but does nothing of relevance (a). The participant remains in contact with a partner (Mi) to make turns (Ea). 


\section{APPENDIX C}

\section{Event Frequency Chart}

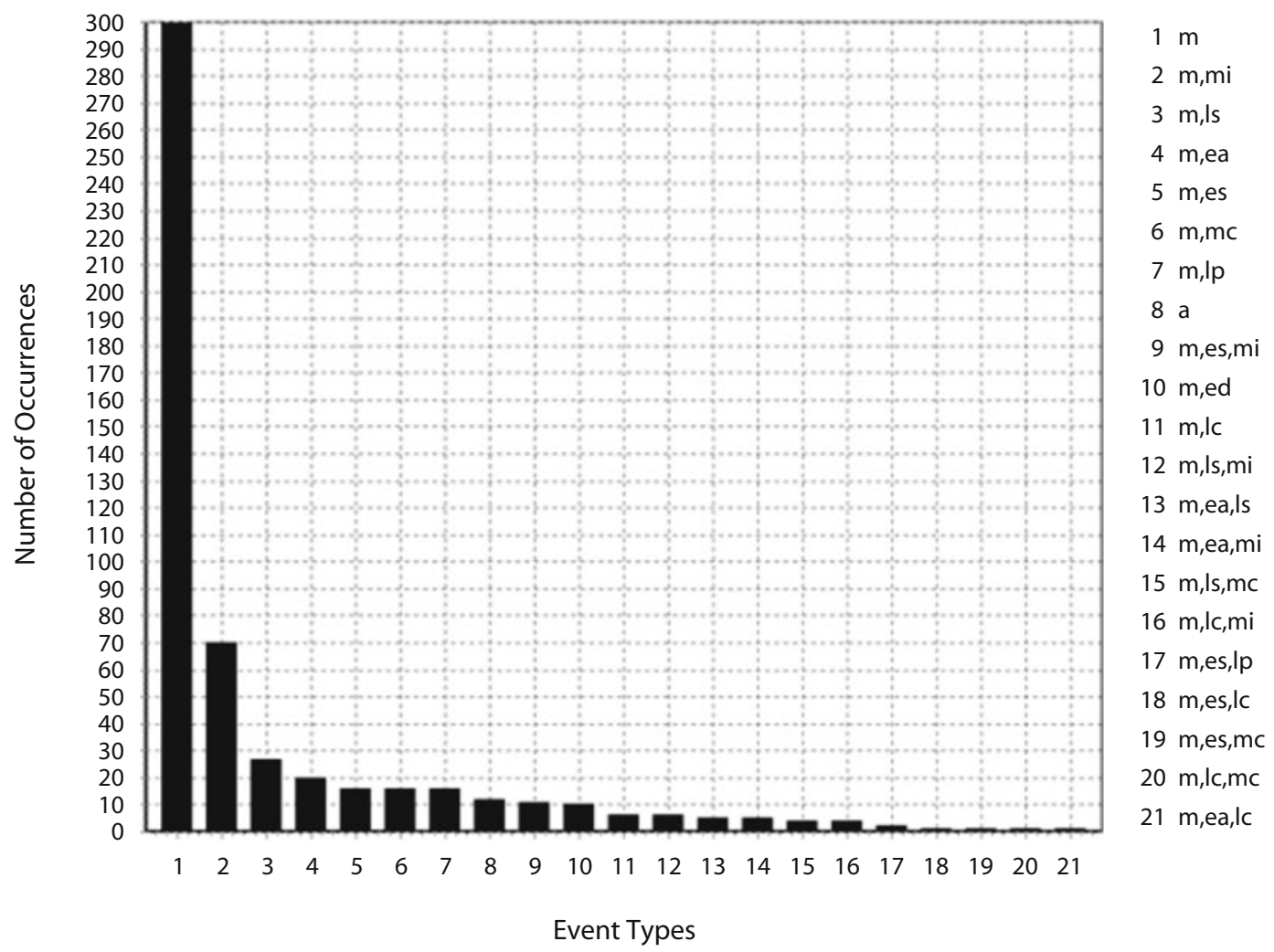

Figure C1. Event frequency chart for metaphoric instructions show that responses that do not agree with the teacher's proposals are not as frequent as are responses to other instructions, probably because the metaphor helps students understand the task. Stability and locomotion motor skills also appear here. An example would be: The participant stands up (Es), starts to turn on his vertical axis (Ea), then runs to another side of the space (Ls).

(Manuscript received October 30, 2008;

revision accepted for publication April 21, 2009.) 